\title{
Elas: introdução à engenharia da computação e além
}

\author{
Thiago Luís Lopes Siqueira ${ }^{1}$ \\ ${ }^{1}$ Instituto Federal de Educação, Ciência e Tecnologia de São Paulo (IFSP) \\ IFSP Câmpus Piracicaba - 13.414-155 - Piracicaba-SP - Brasil \\ prof.thiagodifsp.edu.br
}

\begin{abstract}
Elas" is a set of educational interventions to support women in higher education Computing courses. These interventions are both on curricular (class) and extracurricular (round-table and event) activities of the Computer Engineering course. In this paper, we describe these interventions and report the experiences. In particular, our report is about the class of the first semester belonging to an undergraduate course whose offering had just started.
\end{abstract}

Resumo. "Elas" é um conjunto de intervenções educacionais e de apoio a mulheres no ensino superior em Computação. As intervenções incidem tanto nas atividades curriculares (aula de um componente curricular) quanto nas extracurriculares (mesa-redonda e evento) do curso de bacharelado em Engenharia de Computação. Neste artigo são descritas as intervenções e relatadas as experiências. Em particular, os relatos se referem a uma turma ingressante no primeiro ano de oferecimento do curso.

\section{Introdução}

No contexto mundial, os estados-membros da Organização das Nações Unidas definiram objetivos de desenvolvimento sustentável. Dentre eles, "alcançar a igualdade de gênero e empoderar todas as mulheres e meninas" . No Brasil, notadamente a Sociedade Brasileira de Computação desenvolve programa específico para atrair mulheres para a Computação e despertar o interesse delas pelas diferentes subáreas e profissões relacionadas (RIBEIRO et al., 2019).

No âmbito das instituições de ensino, as políticas de ações afirmativas assumem como princípios o convívio e respeito às diversidades étnica, sexual e de gênero. Dentre outros objetivos, tais políticas incentivam o acompanhamento à permanência de estudantes durante o percurso formativo. Também destacam a relevância da promoção de debates sobre diversidade nos currículos. Além disso, zelam pelo êxito e pela inserção profissional dos(as) estudantes egressos(as) (PDI, 2019).

Nessas instituições, alguns cursos superiores de Computação têm carga horária de 3.200h e duração de cerca de 5 anos (CURI, 2016). Tais cursos são fundamentais diante da necessidade de educar mulheres numa política estratégica para o desenvolvimento e competitividade nacional e regional. Nesses cursos, projetos extracurriculares são desenvolvidos para aumentar o engajamento das mulheres matriculadas (AVELINO; SALGADO; BRAVO, 2019). Por outro lado, considerando a extensa carga horária desses cursos, nota-se que também existem oportunidades para valorizar a participação feminina no decorrer de seus componentes curriculares.

Estudos conduzidos para realçar a participação e a contribuição histórica das

\footnotetext{
${ }^{1}$ https://nacoesunidas.org/pos2015/ods5/
} 
mulheres na Computação são especialmente inspiradores para elas (LOUZADA et al. 2014). Conhecer o perfil das alunas ingressantes é indispensável para traçar estratégias de permanência e êxito (FIGUEIREDO et al., 2016). Não é raro que alunos e alunas ingressantes nos cursos superiores jamais tivessem antes refletido ou discutido sobre a falta de mulheres em TI, ou sobre a decisão de se matricular num curso cujo público é majoritariamente masculino (AVELINO; SALGADO; BRAVO, 2019). Em especial, as ingressantes podem carecer de atenção específica, evidenciando uma oportunidade para oferecer acolhimento, visando permanência e êxito (extrapolando a atração).

Diante do exposto, neste artigo são descritas intervenções educacionais e relatadas experiências num curso de bacharelado em Engenharia de Computação, isto é:

- a preparação e a ministração de aula sobre História da Computação, cujo conteúdo abordou mulheres e suas contribuições à Computação;

- o planejamento e a realização de uma mesa-redonda com $50 \%$ de integrantes mulheres, visando esclarecer o perfil do egresso do curso; e

- a participação num evento externo à instituição, ministrado por profissionais mulheres da área da Computação.

"Elas" é um conjunto de intervenções educacionais e de incentivo a mulheres no ensino superior em Computação. Destacam-se três particularidades. A primeira, que as intervenções incidem tanto nas atividades curriculares (aula de um componente curricular) quanto nas extracurriculares (mesa-redonda e evento). A segunda, que as intervenções são focadas nas ingressantes do curso. A terceira, que o relato se refere à primeira turma ingressante no curso. Logo, as atividades concebidas e realizadas não apenas visam promover engajamento e atração de jovens. Elas também fundamentam a criação de uma cultura que preze pelo acolhimento e permanência das alunas do referido curso, para que estas alcancem êxito.

Este artigo está organizado conforme segue. A Seção 2 aborda o planejamento e a realização da aula. A Seção 3 enfoca na mesa-redonda. A Seção 4 discorre sobre a participação num evento. A Seção 5 discute a permanência e o êxito das estudantes. A Seção 6 compreende a conclusão e os trabalhos futuros.

\section{Aula: Mulheres e suas Contribuições na História da Computação}

Nesta seção, são descritas intervenções sobre os objetivos, o conteúdo programático, e as aulas do componente curricular Introdução a Engenharia da Computação. Sucintamente, o componente tem por objetivos conscientizar ingressantes no que diz respeito ao curso, à instituição, aos conceitos básicos da Computação, e à atividade profissional do(a) engenheiro(a) de computação. Seu conteúdo programático engloba: caracterização do curso e da atividade profissional; histórico dos computadores; definições de hardware e software; sistemas de numeração; e questões ambientais.

As intervenções descritas a seguir convergem na preparação e ministração de uma aula sobre a História da Computação, com ênfase às mulheres e suas contribuições à Computação ao longo dos tempos. Em consonância com Silva (2012), objetivou-se produzir uma narrativa para explicar acontecimentos, e não apenas traçar uma cronologia sem significado. Além disso, buscou-se explorar o que as pessoas já fizeram em Computação, o que se pretende que seja feito, e o que seria possível fazer por ela. A Seção 2.1 discorre sobre a preparação da aula. A Seção 2.2 aborda a realização dessa aula. 


\subsection{Preparação}

A aula expositiva e dialogada tem por objetivos propiciar que alunas e alunos: conheçam a História; compreendam conceitos da Computação; associem pessoas a contribuições; reconheçam as contribuições das mulheres; obtenham estímulo para pesquisar e aprender mais. A preparação da aula requer consulta não apenas a livros, monografias e bases de dados técnico-científicas, mas também a websites, entrevistas, vídeos, podcasts e redes sociais. A fim de despertar o interesse e estimular o engajamento, recomenda-se ministrar a aula na data mais próxima a 8 de março (Dia Internacional da Mulher). A motivação da aula deve atrair a atenção de alunas e alunos para a participação feminina na Computação. O seu desenvolvimento se dá conforme uma ordem cronológica invertida, isto é, começando no presente e remetendo gradativamente ao passado.

As mulheres e contribuições apresentadas devem possuir perfis diversificados, isto é, se caracterizar por diferentes nacionalidades, profissões (academia e mercado), áreas de expertise na Computação, época de destaque, dentre outros aspectos. Deve-se valorizar a mulher brasileira. Cada pessoa citada deve ter sua contribuição contextualizada e associada ao conteúdo programático do componente curricular. Além disso, deve suscitar discussões acerca da formação e da carreira profissional em Computação. A conclusão da aula prevê a realização de atividades.

\subsection{Realização}

A realização da aula ocorre conforme segue. Primeiramente, como motivação, a turma é convidada a citar personalidades e suas contribuições para a Computação. Não se delimita período histórico nem se especifica gênero. As respostas da turma são escritas na lousa. Ao término das respostas, comenta-se a predominância de gêneros ou períodos contidos nelas. A seguir, são apresentadas informações recentes sobre a participação das mulheres nos cursos e a fração de profissionais mulheres em Computação (SILVEIRA, 2018).

Ainda na etapa da motivação, descreve-se sucintamente o contexo atual de aplicações de IoT (internet of things, internet das coisas) e big data. Destacam-se a obtenção de dados por dispositivos diversos, a comunicação e transferência de dados entre eles, e o armazenamento de e consulta sobre enormes volumes de dados. Como exemplo, cita-se o smartphone e seus recursos de sensores e aplicativos, por ser um dispositivo cada vez mais utilizado por jovens no Brasil. Descrever a realidade atual colabora para que a turma se situe como parcela relevante dentre os consumidores de produtos e serviços de tecnologia de informação. Além disso, permite chamar atenção da turma para que vislumbrem se transformarem em produtores dessas tecnologias também, por meio da graduação. Antes da cronologia, são apresentados os objetivos da aula.

A cronologia reversa começa no ano corrente, destacando Paula Bellizia ${ }^{2}$, e sua atuação na Microsoft como vice-presidente de vendas, marketing e operações na América Latina. Comenta-se o seu trabalho pela democratização das tecnologias de inteligência artificial. Argumenta-se que o curso de graduação na área de Computação foi parte relevante das trajetórias acadêmica, profissional e pessoal dela. Enfatiza-se ainda a liderança exercida por uma mulher brasileira com formação em Computação numa empresa relevante mundialmente. Contudo, pode ocorrer uma dificuldade de projetar um futuro como o da vice-presidente, quando o ponto de partida presente é o primeiro ano de

\footnotetext{
${ }^{2}$ https://www.linkedin.com/in/paulabellizia
} 
graduação e as primeiras semanas de aula.

Tal distanciamento entre presente e futuro pode ser encurtado apresentando-se, na sequência, as duas primeiras tecnólogas em análise e desenvolvimento de sistemas egressas do câmpus, em 2016 (OLIVEIRA et al., 2018). Andrezza já atuou como software tester, tendo mudado de área profissional para trabalhar nos EUA, e personifica uma carreira vinculada à iniciativa privada, com ênfase na readaptação e na internacionalização. Hellen personifica uma carreira dedicada aos jogos eletrônicos: é desenvolvedora numa empresa, é doutoranda e sua pesquisa envolve jogos e inteligência artificial, e mantém um blog. Em comum com a turma ingressante que participa da aula, as egressas também frequentaram os mesmos espaços e interagiram com o mesmo corpo docente. Apenas 4 anos se passaram desde a formatura delas.

Com intuito de destacar uma liderança acadêmica em adição à corporativa, apresenta-se a docente Claudia Bauzer Medeiros ${ }^{3}$. São ressaltados a sua admissão na Ordem Nacional do Mérito Científico, como comendadora em 2008, e o exercício da presidência da Sociedade Brasileira de Computação de 2003 a 2007. Cita-se a primeira edição do WIT (Women in Information Technology - Mulheres em Tecnologia da Informação). No âmbito científico, são comentadas suas contribuições para eScience, permitindo abordar a interdisciplinaridade da Computação. No contexto das orientações, comenta-se o incentivo dela para seus orientandos interagirem e superarem a timidez.

O conhecimento técnico colocado em prol da mobilização feminina é posto em evidência na descrição de Anita Borg. São abordados sua comunidade Systers de 1987, o sistema de mensagens MECCA de 1992, e a fundação em 1997 de uma organização para incentivo à representatividade feminina na Computação. Anita possibilita comentar a formação acadêmica (doutoramento) e o trabalho em corporações, ambos relacionados ao conhecimento técnico-científico em sistemas operacionais. A comunidade Systers é descrita como uma iniciativa para que mulheres altamente qualificadas em computação trocassem mensagens sobre o trabalho (ABBATE, 2003). Já o sistema de troca de mensagens MECCA, baseado em serviços de e-mail, elucida a criação e o gerenciamento de comunidades virtuais (BORG, 1992). Este é comparado em partes às redes sociais atuais. $O$ anseio para que mulheres obtivessem maior de representatividade na Computação, dentre outras metas, motivou Anita a fundar uma instituição ${ }^{4}$.

Em seguida, apresenta-se Carol Shaw, considerada uma das pioneiras dentre as desenvolvedoras de jogos eletrônicos. Seu trabalho nessa indústria a conecta à egressa Hellen. Seu relato sobre ter sido menosprezada por um chefe (EDWARDS, 2011) realça a importância da busca por representatividade defendida por Anita. E suscita também um debate em sala de aula, que deve convergir para um posicionamento da turma: zelar por um ambiente sadio e acolhedor para as mulheres durante e após a graduação. A partir do icônico jogo River Raid, de 1982, do qual Carol participou do desenvolvimento, desafiase a turma: como desenvolver software para um hardware limitado como era o console Atari 2600 e seus 128 bytes de memória RAM? Para ilustrar, pergunta-se quantas variáveis do tipo de número inteiro seria possível manter, tendo em vista que a turma cursa simultaneamente o primeiro componente curricular de programação.

Um retorno de aproximadamente dois decênios na história remete à irmã Mary

\footnotetext{
${ }^{3}$ https://www.ic.unicamp.br/ cmbm/

${ }^{4}$ http://anitab.org/
} 
Kenneth Keller, freira, e primeira estadunidense a se tornar doutora em Ciência da Computação, em 1965 (GÜRER, 1995). Os algoritmos da tese dela foram implementados na linguagem Fortran63. Beneficiada por uma permissão concedida pela Dartmouth University, pôde trabalhar no centro de ciência da computação na década de 1950 e participar do desenvolvimento da linguagem BASIC. Ela também vislumbrou aplicações futuras da Computação voltadas à Educação e à Inteligência Artificial. O exemplo de Mary elucida o acesso ao ensino superior e o êxito. Permite também versar sobre linguagens diferentes daquelas que a turma ingressante vem aprendendo.

Se o doutoramento em Computação era um tabu a ser superado, atuar em órgãos militares já não era um desafio para Grace Murray Hopper. Professora, contra-almirante, e analista de sistemas, ela previu a necessidade futura de linguagens de programação de alto nível. Foi responsável pela criação da linguagem FLOW-MATIC, lançada em 1955, única linguagem de processamento de dados de negócios àquela época. Influenciou diretamente na especificação da linguagem COBOL (GÜRER, 1995). Antes, serviu à marinha estadunidense, tendo sido designada para programar o computador Harvard Mark I a partir de 1943, sob a pressão da II Guerra Mundial. Seu exemplo permite introduzir conceitos sobre compiladores, comparar linguagens de programação, caracterizar o Mark I e compará-lo a computadores atuais. E remeter ao termo bug.

Operar computadores era desafiador. E cumprir o papel deles fazendo todos os cálculos? Virginia Tucker, admitida em 1935 pelo Laboratório Aeronáutico de Langley, compôs o primeiro pool computacional junto de outras quatro colegas (MCLENNAN e GAINER, 2012). Àquela época, computador era uma ocupação, e não uma máquina, cujas atribuições eram a resolução de equações matemáticas e a realização de cálculos à mão (eventualmente usando calculadoras). Comumente, mulheres com formação para ensino de matemática buscavam tal emprego devido ao salário maior, se comparado ao de professora. Por um lado, elas proviam os resultados mais rapidamente e de forma mais precisa do que se realizado por engenheiros. Por outro lado, recebiam salários menores do que os de seus colegas engenheiros.

A demanda por homens na II Guerra Mundial no serviço militar possibilitou o ingresso de muitas mulheres na carreira de computador, inclusive as negras. Porém, houve segregação de espaços físicos e também de cargos (MCLENNAN e GAINER, 2012). Virginia tornou-se recrutadora, visitou instituições de ensino, contratou inúmeras mulheres e as capacitou para se tornarem computadores. Comenta-se com a turma recursos de computação em nuvem, comparando-os aos computadores supracitados. Debate-se a existência de diferença salarial entre profissionais homens e mulheres. Citamse iniciativas de mulheres para atraírem outras para a Computação e capacitá-las.

Um regresso de cerca de 100 anos ao passado remete à condessa Augusta Ada Byron King, a conhecida Ada Lovelace. Em 1943, traduziu um artigo do colega Charles Babbage, do Francês para o Inglês, e redigiu uma sequência de passos e operações para calcular números de Bernoulli (RECHENMANN, 2014). Tal feito ficou conhecido como o primeiro programa de computador (porém, não executado), conferindo a Ada o reconhecimento de primeira programadora. Filha de mãe estudiosa (e religiosa) e pai poeta (e boêmio), Ada foi estimulada desde a infância a estudar lógica.

O encerramento da linha do tempo não retrocede, mas permanece em 1843 . Teresa Cristina se casaria com Dom Pedro II em maio e chegaria ao Brasil em setembro. Relatos sobre a imperatriz comumente citam sua aparência física e seu estereótipo submissa e do 
lar, em detrimento de conhecimentos musicais, erudição e afinidade por leitura e arqueologia (CAMARGO, 2017). Faltavam, ainda: 3 anos para nascer a Princesa Isabel; 28 anos para a Lei do Ventre Livre, pela qual filhos das escravas nasceriam livres; e 45 anos para a Lei Áurea, que declarou extinta a escravidão.

Interrompida a cronologia reversa, compara-se a participação feminina em diferentes contextos e nações, baseando-se nas vivências simultâneas de Ada e Teresa. Convida-se a turma para uma reflexão a respeito da História e do desenvolvimento tecnológico das nações, frente às diferentes realidades que suas mulheres viviam. Não se pode perder de vista que a história das ciências é totalmente conectada com as histórias nacionais, sendo impossível compreendê-las desconectadas das negociações, vivências, memórias e ações sociais (SILVA, 2012).

Conclui-se a aula apresentando-se a bibliografia e recomendando sua leitura para aprofundamento. São propostos exercícios de fixação e tarefas. Uma delas consiste em pesquisar e adicionar uma mulher e suas contribuições à linha do tempo. Indica-se também uma filmografia, mencionando-se Alan Turing e convidando a turma para conhecer a sua história e suas contribuições, também atentando à questão de gênero.

Por um lado, deve-se enfatizar que tanto a aula quanto a cronologia não pretendem ser completas nem tampouco exaustivas sobre as mulheres e suas contribuições à Computação. Também não suprimem aulas nas quais as contribuições históricas à Computação foram protagonizadas por homens, no melhor do conhecimento. Por outro lado, aula e cronologia visam despertar o interesse de estudantes pelo tema. Visam também surpreender o público com informações que ainda não conheciam, ou que não eram capazes de relacionar. Visam motivar as mulheres ingressantes no curso para que se espelhem em exemplos reais de competência e superação. E visam incluí-las num curso de público predominantemente masculino.

\section{Mesa-redonda sobre o Perfil do Egresso}

Nesta seção se descreve outra intervenção: a organização e a realização de uma mesaredonda, objetivando principalmente esclarecer o perfil do egresso do curso para o público. Por um lado, a mesa-redonda é caracterizada como atividade de extensão. Por outro lado, a participação numa mesa-redonda é considerada atividade complementar válida para estudantes do curso.

Foram estabelecidos pré-requisitos para a mesa-redonda conforme segue. Sua composição seria de $50 \%$ de integrantes mulheres, com exceção do(a) moderador(a). Integrantes teriam, obrigatoriamente, graduação na Engenharia de Computação. O perfil profissional das integrantes diferiria do perfil dos integrantes, de modo a evitar sobreposições e valorizar a diversificação. A divulgação não daria destaque especial à presença de uma mulher, embora isso pudesse ganhar a empatia do público feminino. $\mathrm{O}$ público-alvo seria composto por estudantes dos níveis médio e superior, visando tanto atrair novas estudantes quanto motivar a permanência daquelas já matriculadas. A realização seria no semestre subsequente à realização da aula descrita na Seção 2, no mês de outubro, e simultaneamente às ações do Outubro Rosa.

Em conformidade com os pré-requisitos, a $1^{\text {a }}$ Mesa-redonda da Engenharia de Computação foi planejada e realizada conforme segue. $\mathrm{Na}$ seleção e convite de integrantes, houve maior dificuldade para se encontrar uma engenheira de computação, do que um engenheiro de computação. Foi intitulada "Sobre a escolha, a formação e o 
exercício profissional" e teve como integrantes uma engenheira e um engenheiro. A Tabela 1 caracteriza tais integrantes e realça seus perfis diversificados e complementares, conforme fora planejado. O moderador foi o coordenador do curso. Por fim, foi realizada em outubro ${ }^{5}$, em data próxima da Semana Nacional de Ciência e Tecnologia de 2018, cujo tema era coincidentemente Ciência para a Redução das Desigualdades.

Tabela 1. Caracterização de cada integrante da mesa-redonda

\begin{tabular}{|l|c|c|}
\hline Característica & Engenheiro & Engenheira \\
\hline Profissão & $\begin{array}{c}\text { Líder de área de } \\
\text { Machine Learning }\end{array}$ & $\begin{array}{c}\text { Analista de Tecnologia } \\
\text { da Informação }\end{array}$ \\
\hline Setor & Privado & Público \\
\hline Área & Pecuária digital & Educação \\
\hline Tempo desde a graduação & 9 anos & Bacharela \\
\hline Escolaridade & Doutor & $\begin{array}{c}\text { Computação Forense } \\
\text { Análise de Sistemas }\end{array}$ \\
\hline Expertise & Inteligência Artificial & Sim \\
\hline Experiência internacional & Não & .
\end{tabular}

Foram analisados os dados das inscrições na mesa-redonda e do público presente, conforme segue. A intenção de comparecimento foi manifestada via inscrição. Constatouse que, como exibido na Figura 1a, apenas 30\% das inscrições foram de alunas, provenientes dos cursos de Engenharia de Computação, Análise e Desenvolvimento de Sistemas, e Técnico em Informática. O comparecimento foi aferido no evento. Observouse que, dentre o público presente, apenas $20 \%$ eram alunas, como mostrado na Figura $1 \mathrm{~b}$. A participação das alunas matriculadas no curso de Engenharia de Computação também foi aferida, conforme ilustrado na Figura 1c. Estiveram presentes no evento dois terços das alunas. Portanto, embora em menor número diante dos alunos, as alunas do curso demonstraram interesse e foram assíduas ao evento.

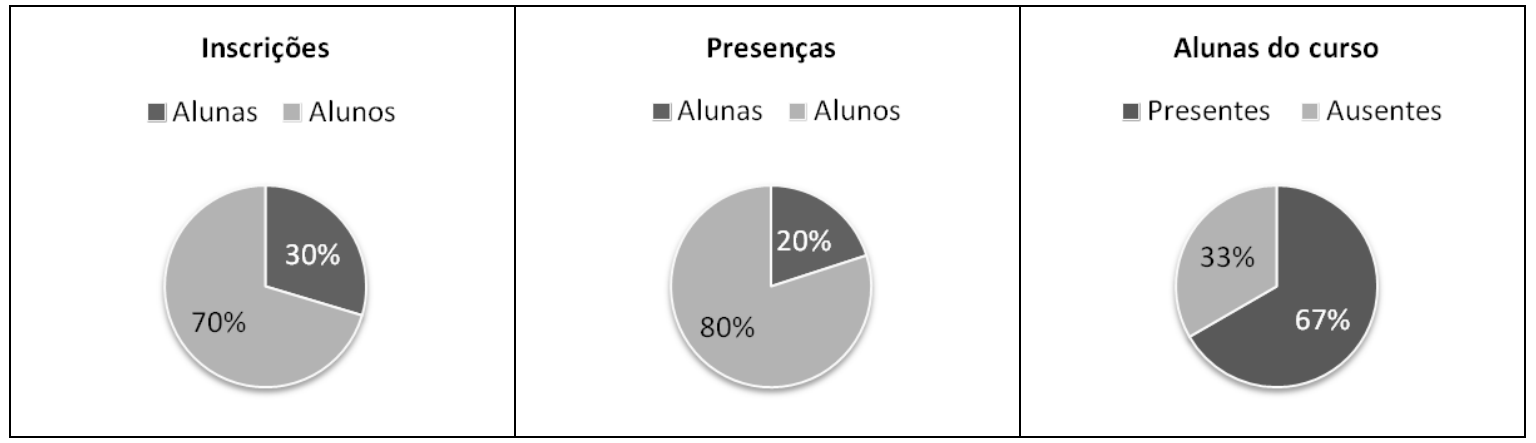

(a) Intenção

(b) Comparecimento

(c) Participação

\section{Figura 1. Mesa-redonda: inscrições e comparecimento}

\section{Participação em evento externo}

Esta seção descreve a participação num evento externo. A educação também objetiva

\footnotetext{
${ }^{5}$ https://prc.ifsp.edu.br/index.php/ultimas-noticias/1190-1-mesa-redonda-da-engenharia-de-computacaoacontece-em-22-10-as-10h
} 
formar cidadãs para o mundo do trabalho e promover a emancipação. Diante dessas premissas, e para futuras profissionais qualificadas se aproximarem pela primeira vez do setor produtivo local, foi selecionado um evento para participação conforme os seguintes requisitos: (i) ter mulheres como público-alvo principal; (ii) ser ministrado por mulheres profissionais da área da Computação; e (iii) objetivar aproximação de academia e indústria. Para incentivar e auxiliar, o grupo de alunas seria acompanhado por docente.

O evento selecionado para participação foi um meetup organizado por um hub de inovação situado no mesmo bairro do câmpus ${ }^{6}$. O evento teve como propósito reunir pessoas interessadas em fomentar o protagonismo da mulher no cenário agropecuário e de tecnologia da informação. As seis profissionais representaram três diferentes segmentos: comunidade técnica de desenvolvimento, corporativo (empresa multinacional), e startup. Dentre as profissionais, estavam duas egressas do câmpus pertencentes ao segmento startup. Todas as profissionais tiveram um período para comentarem sua trajetória profissional e abordar questões intrínsecas às mulheres no mundo do trabalho.

Compareceram ao evento $50 \%$ das alunas do curso. Adicionalmente, uma das alunas trouxe a sua mãe para participar. $\mathrm{O}$ evento possibilitou às alunas conhecer relatos de profissionais que vivenciam a combinação de duas áreas ocupadas predominantemente por homens: agropecuária e tecnologia da informação. Logo, a experiência proporcionada foi além das expectativas iniciais. $\mathrm{O}$ evento proporcionou às alunas um contato com profissionais e o setor produtivo local.

Além disso, viabilizou um encontro entre diferentes gerações. As tecnólogas egressas do câmpus discorreram sobre a trajetória na graduação em Análise e Desenvolvimento de Sistemas, o início da carreira como estagiárias, e a posterior efetivação na startup onde trabalham. Também comentaram sobre o desenvolvimento de software usando tecnologias emergentes em soluções para a pecuária. E, após o evento, aconselharam as estudantes de Engenharia de Computação a se dedicarem durante o curso e contarem com o apoio do corpo docente, enfatizando benefícios à formação.

\section{Permanência e Êxito}

Nesta seção, são apresentados e discutidos dados a respeito da permanência e êxito das estudantes que participaram das intervenções anteriormente citadas. Para além do engajamento e atração de mulheres, imprescindível se torna acompanhar a permanência dessas estudantes no curso, bem como aferir como progridem nele.

A turma que vivenciou as intervenções em 2018 está no quinto semestre atualmente, sendo que o curso tem duração de 10 semestres. Com relação à permanência, atualmente, $83 \%$ das alunas ingressantes na primeira turma prosseguem matriculadas. Embora 17\% tenham deixado a instituição, se transferiram para o mesmo curso noutra instituição. Logo, $100 \%$ daquelas que optaram inicialmente pela Engenharia de Computação persistem no mesmo curso, embora uma parte esteja vinculada a outra universidade. Houve zero desistente.

Dois anos após a primeira intervenção (aula descrita na Seção 2) foi realizada uma reunião com as estudantes daquela primeira turma. Elas foram informadas que a turma ingressante no presente semestre participaria de uma aula similar àquela que tiveram.

\footnotetext{
${ }^{6}$ https://prc.ifsp.edu.br/index.php/ultimas-noticias/1257-alunas-e-ex-alunas-participaram-de-encontrosobre-a-mulher-na-area-de-ti
} 
Foram também consultadas e se manifestaram conforme segue. Todas concordaram sobre a importância daquela aula, tanto em conteúdo quanto em motivação. Consentiram que o conteúdo apresentado era inédito no melhor do conhecimento delas à época, e que foi bastante inspirador para quem começava o curso.

Em decorrência da pandemia de Covid-19 e da suspensão das atividades letivas presenciais, a referida aula precisou ser adiada. Contudo, foi agendado um diálogo em rede para compartilhamento de experiências acadêmicas e profissionais. O público-alvo definido foi de estudantes do ensino médio e do primeiro ano da graduação. Duas alunas daquela primeira turma se voluntariaram e ministraram a atividade online junto de mais um aluno. Tal fato realça que houve empoderamento dessas alunas. Um dos propósitos da atividade foi atrair mulheres para ingressarem na Engenharia de Computação.

Para aferição do êxito, foi levado em consideração o percentual de progresso no curso. Tal medida consiste na carga horária cumprida com aprovação nos diferentes componentes curriculares do curso. As estudantes obtiveram percentual médio de aproximadamente $40 \%$ (sendo o mínimo de $35 \%$, e o máximo de $44 \%$ ). Tais resultados evidenciam que as estudantes vêm progredindo no curso e cumprindo as etapas de formação. Acrescenta-se que $40 \%$ dessas estudantes já realizam o estágio curricular supervisionado obrigatório. Logo, já vivenciam o setor produtivo e projetos compatíveis com a formação, bem como adquirem experiência profissional no mundo do trabalho.

\section{Conclusão}

Este artigo abordou um conjunto de intervenções educacionais e de apoio a mulheres no ensino superior. Além disso, foram relatadas as experiências vivenciadas a partir da realização dessas intervenções no curso de Engenharia de Computação. Particularmente, tais experiências enfocaram estudantes ingressantes no curso (primeiro semestre) e a primeira turma que ingressou no curso.

As intervenções foram diversificadas e incidiram tanto sobre atividades curriculares quanto extracurriculares. Ou seja, parte da carga horária do curso. A principal intervenção consistiu numa aula de História da Computação centrada nas mulheres e suas contribuições. Para tal, foi delineada uma cronologia reversa com protagonistas em nível local/regional, nacional e internacional. Uma cronologia dotada de contexto tecnológico, social, econômico. E relacionada aos demais conteúdos do componente curricular de Introdução à Engenharia de Computação, bem como de outros componentes. Uma cronologia não exaustiva, mas convidativa: para estudantes (leitoras, leitores e autores) pesquisarem e adicionarem outras mulheres e contribuições, dentre as tarefas.

Além disso, foi realizada uma mesa-redonda com $50 \%$ de integrantes mulheres para esclarecimento do perfil do egresso. A ela compareceram dois terços das estudantes do curso, embora o público presente tenha sido majoritariamente masculino. Visando colaborar para tais estudantes conhecerem o mundo do trabalho e o setor produtivo local, organizou-se a participação num evento externo ministrado para o público feminino. A participação permitiu às estudantes o contato com o setor produtivo local, e conhecer mulheres profissionais de tecnologia da informação dotadas de diferentes expertises e graus de experiência. Mais que isso, permitiu contato com egressas do câmpus.

Às intervenções descritas neste artigo, atribuiu-se o nome "Elas". Elas entraram no curso junto das estudantes ingressantes, da primeira turma, na disciplina de introdução. Elas seguiram além, promovendo engajamento também fora da sala de aula, e até mesmo 
fora da instituição. Acompanharam o progresso das estudantes até quase a metade do curso. Proveram inspiração às estudantes e constataram que as estudantes vêm progredindo no curso. Futuramente, almeja-se que elas considerem mais mulheres latinoamericanas e africanas na cronologia da aula. Espera-se que elas se tornem uma estratégia de ensino para promover atração e permanência de mulheres. Que se multipliquem noutros componentes curriculares e atividades extracurriculares, creditando às mulheres conceitos, técnicas e metodologias da Computação.

\section{Referências}

Avelino, Meirylene, Salgado, Luciana and Bravo, Raquel (2019) Factors Affecting Female Students Motivation Related to Enrollment and Retention in Information Technology Courses. CLEI Electronic Journal, v.22, n.2, 8.

Abbate, Janet (2003) Women and Gender in the History of Computing. IEEE Annals of the History of Computing, v.25, n.4, p.4-8.

Borg, Anita. MECCA: a message-enabled communication and information system. http://www.hpl.hp.com/techreports/Compaq-DEC/NSL-TN-10.pdf .

Camargo, Lucas S. (2017) Teresa Cristina: a imperatriz, a mulher e as sombras do II Império Brasileiro. Monografia, Graduação, INHIS-UFU, Uberlândia, MG. 46p.

Curi, Luiz R. L. (2016) Resolução No 5, de 16 de novembro de 2016: Diretrizes Curriculares Nacionais para os cursos de graduação na área da Computação.

Edwards, Benji (2011) Carol Shaw, Atari's First Female Video Game Developer. http://www.vintagecomputing.com/index.php/archives/800/vcg-interview-carol-shawfemale-video-game-pioneer-2 .

Figueiredo, Renata V. et al. (2016) Um estudo inicial sobre as alunas ingressantes no curso de Licenciatura em Ciência da Computação da Universidade Federal da Paraíba . In X Women in Information Technology (WIT), Porto Alegre, p.2741-2745.

Gürer, Denise (1995) Pioneering Women in Computer Science. Communications of the ACM, v.38, n.1, p.45-54.

Louzada, Carolina S. et al. (2014) Um mapeamento das publicações sobre o ingresso das mulheres na computação. VI Congresso da Mulher Latino-americana em Computação (LAWCC), Montevidéu, 12p.

McLennan, Sarah and Gainer, Mary (2012) When the Computer Wore a Skirt: Langley's computers, 1935-1970. NASA History Program Office News \& Notes, v.29, n. 1.

Oliveira, Vinícius. J. R., Porto, Adilson S., Santos, Karoliny D., Siqueira, Thiago L. L. (2018) Um sítio eletrônico para os egressos do IFSP Câmpus Piracicaba. In V Congresso de Extensão e Mostra de Arte e Cultura do IFSP (CONEMAC), Barretos, 3p.

PDI (2019) Plano de Desenvolvimento Institucional 2019-2023 do IFSP.

Ribeiro, Karen et al. (2019) Uma análise de gênero a partir de dados da Sociedade Brasileira de Computação. In XIII Women in Information Technology (WIT), Belém, p. 159-163.

Rechenmann, François (2014) Le premier article scientifique de l'histoire de l'informatique ? Calcul et informatique, Mars.

Silva, Márcia R. B. (2012) Para que fazer história da informática? In II Simposio de Historia de la Informática en América Latina y Caribe (SHIALC), Medellin, p.10-16.

Silveira, E. (2018) Como as mulheres passaram de maioria a raridade nos cursos de informática. BBC Brasil. https://www.bbc.com/portuguese/geral-43592581 . 